\title{
Relação da percepção auditiva com a consciência fonoarticulatória de criança com desvio fonológico
}

\author{
Relationship of auditory perception with speech-language awareness of children with phonological \\ deviation
}

Relación de la percepción auditiva con la conciencia del habla y el lenguaje de los niños con desviación fonológica

Recebido: 15/01/2021 | Revisado: 19/01/2021 | Aceito: 22/01/2021 | Publicado: 28/01/2021

\author{
Waldenia Lima de Castro \\ ORCID: https://orcid.org/0000-0002-8508-8122 \\ Faculdade do Ensino Superior do Piaú, Brasil \\ E-mail: waldeniaalmeida100@hotmail.com \\ Claudia Catão de Aguiar Sousa \\ ORCID: https://orcid.org/0000-0002-6193-7484 \\ Faculdade do Ensino Superior do Piauí, Brasil \\ E-mail: klaudyakatao@hotmail.com \\ Ruth Raquel Soares de Farias \\ ORCID: https://orcid.org/0000-0002-0988-0900 \\ Faculdade do Ensino Superior do Piauí, Brasil \\ E-mail: ruthraquelsf@gmail.com
}

\begin{abstract}
Resumo
O presente estudo analisou a relação da percepção auditiva com a consciência fonoarticulatória de criança com desvio fonológico. Desse modo, investigou porque a criança precisa em cada faixa etária fazer a aquisição dos fonemas corretos; conheceu a relação entre a percepção auditiva e a função aprendida da fala; compreendeu como os recursos fonoterápicos podem ajudar na percepção auditiva da fala de criança com desvio fonológico. Adotou-se como método a revisão integrativa. Todos os artigos selecionados foram lidos minuciosamente e se realizou uma padronização dos conteúdos encontrados conforme os objetivos propostos. Os resultados demonstraram que desvios fonológicos em crianças podem estar relacionados a falhas na percepção auditiva que, por sua vez, influenciam negativamente no desenvolvimento da consciência fonológica. Constou-se que existem diversos recursos fonoterápicos como o Sistema de Estimulação NeuroAditiva (SENA@), o Software Auxiliar na Reabilitação de Distúrbios Auditivos (SARDA, o VoiceOnset Time (VOT) que podem ajudar na percepção auditiva da fala de criança com desvio fonológico.
\end{abstract}

Palavras-chave: Percepção auditiva; Consciência fonoarticulatória; Desvio fonológico em crianças.

\begin{abstract}
The present study analyzed the relationship between auditory perception and phonoarticulatory awareness of children with phonological disorders. Thus, he investigated why the child needs, in each age group, to acquire the correct phonemes; knew the relationship between auditory perception and the learned function of speech; understood how speech therapy resources can help in the auditory perception of the speech of children with phonological disorders. Integrative review was adopted as the method. All selected articles were carefully read and the contents found were standardized according to the proposed objectives. The results showed that phonological disorders in children may be related to failures in auditory perception, which, in turn, negatively influence the development of phonological awareness. It was found that there are several phonotherapy resources such as the NeuroAditive Stimulation System (SENA ()), the Auxiliary Software in the Rehabilitation of Auditory Disorders (SARDA, VoiceOnset Time (VOT) that can help in the auditory perception of the speech of children with phonological disorders.
\end{abstract}

Keywords: Auditory perception; Speech-language awareness; Phonological deviation in children.

\section{Resumen}

El presente estudio analizó la relación entre la percepción auditiva y la conciencia fonoarticulatoria de niños con trastornos fonológicos. Así, investigó por qué el niño necesita, en cada grupo de edad, adquirir los fonemas correctos; conocía la relación entre la percepción auditiva y la función aprendida del habla; comprendió cómo los recursos de logopedia pueden ayudar en la percepción auditiva del habla de niños con trastornos fonológicos. Se adoptó como método la revisión integradora. Todos los artículos seleccionados fueron leídos atentamente y se llevó a cabo una estandarización de los contenidos encontrados de acuerdo con los objetivos propuestos. Los resultados mostraron que 
los trastornos fonológicos en los niños pueden estar relacionados con fallas en la percepción auditiva, lo que, a su vez, influye negativamente en el desarrollo de la conciencia fonológica. Se encontró que existen varios recursos de fonoterapia como el Sistema de Estimulación NeuroAditiva (SENA @), el Software Auxiliar en la Rehabilitación de Trastornos Auditivos (SARDA, VoiceOnset Time (VOT) que pueden ayudar en la percepción auditiva del habla de niños con trastornos fonológicos.

Palabras clave: Percepción auditiva; Conciencia del habla y el lenguaje; Desviación fonológica en niños.

\section{Introdução}

A comunicação é uma habilidade humana conquistada ao longo dos séculos e importante mecanismo de interação social. Contudo, nem sempre os seres humanos falaram, pois nos primórdios da civilização os gestos e sons guturais foram seus primeiros meios de se comunicarem. Em sua evolução, com o passar dos anos os homens foram desenvolvendo signos linguísticos, e com eles a fala devido a sua capacidade mental. No entanto, a capacidade de se comunicar verbalmente só foi possível devido à estrutura anatômica do aparelho vocal que lhe possibilitou articular os sons necessários para falar (Afonso, 2015).

Dessa forma, deve-se frisar que a aquisição da fala é uma característica humana, e que a criança ouvinte aprende a falar e se comunicar por meio das relações sociais que tem com os pais e outros membros da família, bem como através das experiências com o mundo a sua volta. Com a aquisição da linguagem ela passa tanto a desenvolver seu pensamento, sua subjetividade, quanto sua capacidade de simbolização (Lacerda \& Nascimento, 2016).

Ao adquirir a capacidade de se comunicar a criança passa a desenvolver mecanismo cognitivos que lhe permitem realizar a construção de padrões fonológicos. Ela manifesta elaborações intermediárias que sugerem variações relacionadas a um determinado som, isto é, a fala. Assim, no momento em que a criança está aprendendo a se comunicar mediante a linguagem oral ela está aprendendo a representá-la mentalmente, e a discriminar e armazenar as categorias específicas que formam os padrões fonológicos (Silva \& Guimarães, 2013).

Para que isso ocorra à audição é uma função essencial, pois ela é um requisito importante para que haja o desenvolvimento da linguagem, já que é decisiva na aquisição da fala. Mas só a audição não o bastante para que a criança analise e interprete sons, também é necessário que ela desenvolva uma série de habilidades conjuntas que forma o Processamento Auditivo (PA), que é uma forma como o cérebro discrimina as informações auditivas que lhe chegam por meio do ouvido (Terto \& Lemos, 2011).-

Essa capacidade de discriminar os sons da fala e refletir sobre eles denomina-se consciência fonológica, também conhecida como uma habilidade capaz de permitir aos seres humanos pensar, refletir e agir sobre os sons provenientes da fala. Possuindo diferentes níveis essa habilidade pode ser caracterizada em diferentes dimensões: a consciência da palavra, da sílaba, das unidades intrassilábicas e do fonema. Crianças que apresentam alterações na fonologia devem ser reconhecidas como tendo o denominado desvio fonológico (Souza, Mota \& Santos, 2011).

Vale destacar, que a partir da idade de 4 anos de idade a maioria das crianças já possui seu sistema fonológico formado. Entretanto, algumas delas apresentam alterações de fala que persistem e vão além dessa idade. Crianças como essas podem ser caracterizadas tendo desvio fonológico, uma vez que apresenta dificuldades em organizar o sistema de sons de sua língua, e não apresentam fatores orgânicos identificáveis como, deficiência auditiva, anormalidades anatômicas e funcionais, capazes de interferir em sua fala (Pagliarin et al., 2010).

Crianças com desvio fonológico apresentam com frequência atraso no desenvolvimento da consciência fonológica interferindo no seu processo de desenvolvimento da língua escrita. Na fase escolar é importante ficar atento a crianças com desvio fonológico, pois ele evidencia alterações no sistema fonológico envolvendo tanto a produção do som quanto a percepção da fala, interferindo também na organização e compreensão das regras fonológicas, que denota a necessidade de acompanhamento educacional a fim de ser verificada a evolução do seu desenvolvimento da língua e da produção escrita 
(Mezzomo, Mota \& Dias, 2010).

Alguns métodos como o Sistema de Estimulação NeuroAditiva (SENA@) e a Terapia fonético/articulatória (TA) podem ajudar no tratamento de desvios fonológicos pois contribuem para o rendimento em atividades voltadas à interpretação do som e distúrbios de causa fonética (Giacchini, Mota \& Mezzomo, 2011).

Com base nas afirmativas acima o objetivo do presente estudo é analisar a relação da percepção auditiva com a consciência fonoarticulatória de criança com desvio fonológico. Para tanto, buscou-se investigar porque a criança precisa em cada faixa etária fazer a aquisição dos fonemas corretos; conhecer a relação entre a percepção auditiva e a função aprendida da fala; compreender como os recursos fonoterápicos podem ajudar na percepção auditiva da fala de criança com desvio fonológico.

A presente pesquisa foi movida pelo interesse científico da pesquisadora em compreender e refletir mais claramente sobre a relação da percepção auditiva com a consciência fonoarticulatória de criança com desvio fonológico.

\section{Percepção Auditiva e Fala}

A comunicação entre os seres humanos é uma habilidade inata. Sua importância é tal que por meio dela as pessoas interagem, se integram e ampliam seus conhecimentos adquirindo novas experiências através das trocas de informações e experiências contidas na recepção e transmissão da linguagem. A linguagem oral é forma mais comum de comunicação entre as pessoas e envolve tanto a fala quanto a percepção auditiva, podendo-se dizer que existe uma relação de interdependência entre elas (Terto \& Lemos, 2011).

Nesse contexto é muito importante o sistema auditivo, que formado por um ouvido externo composto pela orelha, também conhecida como pavilhão auditivo, o conduto auditivo e o tímpano. É esse sistema que media a comunicação entre os indivíduos e é responsável pela percepção e sensação de estímulos sonoros, permitindo que o ouvinte detecte vários e diferentes tipos de sons (Errobidart et al., 2014).

O sistema auditivo é constituído por minúsculas estruturas sensoriais e conexões centrais que são responsáveis pelo fenômeno da audição, e se encontra divido em três níveis: o periférico que capta os estímulos; tronco cefálico, por sua vez, se responsabiliza pela ocorrência da fase inicial do processo de audição por meio da modulação e assimilação dos sinais; já o tálamo-cortical é o local onde os estímulos sensoriais podem gerar respostas, tanto emocionais, quanto cognitivas ou mesmo linguísticas (Buriti \& Rosa, 2014).

Para que haja o desenvolvimento adequado da linguagem oral e escrita se faz necessário que o sistema auditivo, tanto periférico quanto central, esteja funcionando bem. Qualquer alteração afetando a função auditiva pode influenciar na organização do complexo sistema de aprendizado humano (Cisneyros et al., 2016).

O sistema auditivo periférico é composto pelas estruturas da orelha externa, média, interna e nervo vestibulococlear, que são incumbidos de captar, transmitir e processar a onda sonora que ocorre na cóclea e porção coclear do nervo vestibulococlear, situado na região temporal da cabeça (Carvalho, Novelli \& Santos, 2015).

Já o sistema auditivo central é formado por vias aferentes. Essas transportam de modo ascendente as informações criadas no ramo coclear do nervo auditivo, sob a forma de potencial de ação, que chegam até o sistema nervoso central e depois se dirigem ao córtex. Por sua vez, as vias nervosas eferentes fazem o inverso retornando a resposta do tronco encefálico pelas vias subcorticais, córtex auditivo, lobo temporal e corpo caloso ao nível periférico (Oliveira et al., 2013).

A percepção auditiva diz respeito ao processamento de sinal acústico audível, se inicia mediante células receptoras sensíveis a um estímulo específico. Seu processamento se dá por meio de uma série de conexões neuromáticas que tem origem nos neurônios da cóclea, e finaliza no córtex auditivo cerebral. Assim, envolve o sistema nervoso auditivo (SNAP) e sistema nervoso auditivo central (SNAC). Esse último é o responsável pela detecção e discriminação do som (Buriti \& Rosa, 2014).

Quanto à fala, deve-se dizer que aprender a falar também é aprender a se relacionar com o mundo a sua volta e a 
desempenhar papéis e condutas. Isso porque a linguagem expressada na fala exige a coordenação de várias aptidões e funções, assim como a intervenção de vários órgãos. A fala deve ser interpretada como a produção coordenada de movimentos denominados de gestos articulatórios e emissões vocais laríngeas. Estes produzem a acústica vocal bem como e o timbre articulatório, dos ressonadores sobre a boca (Souza, 2009).

Por um lado, a fala está relacionada à evolução e manutenção do cérebro, ocorrendo devido a coordenação dos órgãos bucofonatórios. Por outro lado, acontece em virtude dos progressos presentes no desenvolvimento psicomotor e cognitivo. O desenvolvimento da linguagem e, por conseguinte, da fala exige a interação dos aspectos físicos, neurológicos, comportamentais, cognitivos, sociais e afetivos (Goméz \& Terán, 2015).

A fim de que a fala ocorra, os sons que são produzidos nas pregas vocais devem ser modelados e articulados na hora de sua passagem pela laringe, faringe, e cavidades oral e nasal. Essa dinâmica exige que sejam desenvolvidos movimentos físicos apropriados para a emissão dos sons (aspectos fonéticos) (Rabelo et al., 2015).

Embora a audição seja um quesito necessário para o desenvolvimento da fala, não basta que o indivíduo possua limiares auditivos normais para receber, analisar e interpretar os sons, é preciso ainda que ele seja capaz de desenvolver uma série de habilidades conjuntas e específicas que são denominadas de Processamento auditivo (PA) (Terto \& Lemos, 2011).

Muitas crianças podem apresentar transtornos na percepção auditiva ou na fala ocasionando desajustes sociais, dificuldades de aprendizagem da leitura e escrita, repercutindo negativamente no seu desenvolvimento global por não possuírem ou ainda não desenvolverem consciência fonológica, que é a capacidade de pensar, fazer reflexões e manipular de forma consciente os sons da fala (Donicht, Ceron \& Soares, 2019).

É possível apontar ao menos três formas de consciência fonológica: a consciência silábica, traduzida na capacidade que a criança consegue para analisar as palavras em sílabas; a consciência fonêmica, interpretada como uma capacidade que a criança tem de analisar a palavra em unidades de som mesmo que pequenas, no caso, os fonemas; a consciência das unidades intrasilábicas, onde a criança possui a habilidade de analisar as palavras em unidade de som muito menor que as sílabas, e muito mais que os fonemas. Como exemplo tem-se a palavra flor que é formada pelo ataque /fl/ e pela rima /or/ (Moreira, 2013).

\section{Amadurecimento da Consciência Fonoarticulatória nos Desvios Fonológicos de Crianças}

Crianças com alterações na fonologia apresentam o denominado desvio fonológico. Trata-se de um distúrbio na fala da criança onde se constata a presença de omissões e substituições de fonemas que não deveria mais existir por conta da sua idade. Até os três anos de idade a criança já é capaz de discriminar os sons do ambiente e da linguagem. Ela já começa a perceber que possui a capacidade de perceber os sons da fala e discriminá-los de outros sons (Terto \& Lemos, 2011).

A criança que apresenta desvios fonológicos possui em geral idade igual ou superior a 4 anos. Ela tem dificuldades em articular a fala em diferentes graus, e pode apresentar além do referido desvio, alterações na consciência fonológica. Esse desvio deve ser interpretado como uma inadequação do sistema fonológico da criança que promove um padrão de fala espontâneo diferente de um adulto. Ainda não foi identificada nenhuma etiologia do desvio fonológico (Souza, 2009).

Não cabe entender que as dificuldades características do desvio fonológico são geradas por alterações na força ou mobilidade dos órgãos responsáveis em articular a fala, ao contrário são devidas as dificuldades que ela tem na aquisição das consoantes de sua língua de origem (Donicht, Ceron \& Soares, 2019).

O conjunto de habilidades que permite a criança pensar, refletir e agir sobre os aspectos referentes aos sons da fala chama-se consciência fonológica. Essas habilidades abrangem tanto a simples percepção da extensão das palavras e de suas similitudes quanto aspectos mais complexos, como a divisão e utilização de sílabas e fonemas (Souza, Mota \& Santos, 2013).

Qualquer criança exposta a formas linguísticas diferentes em uma dada cultura passa a formar sua consciência fonológica. Esta vai sendo desenvolvida a partir de músicas infantis, dos jogos orais, etc. e da própria fala das pessoas. A 
consciência fonológica diz respeito tanto à consciência de que a fala pode ser dividida quanto à habilidade de empregar estas divisões. Crianças com desvio fonológico apresentam dificuldades no desenvolvimento de habilidades que envolvam a consciência fonológica (Moreira, 2013).

Esse tipo de consciência evolui de modo gradual na medida em que a criança vai desenvolvendo consciência do sistema sonoro da língua, isto é, de palavras, sílabas e fonemas como unidades que podem ser identificadas. A consciência fonológica (CF) se desenvolve em etapas sucessivas, integradas, mas isso não quer dizer que seja de modo linear. Uma das suas etapas evolutivas é a consciência articulatória (CA), responsável pela capacidade que permite o falante refletir sobre as características articulatórias dos fonemas (Souza, Mota \& Santos, 2013).

Além da consciência articulatória há, também, a consciência fonoarticulatória (CFA) que pode ser caracterizada como a habilidade responsável pela diferenciação das articulações dos sons da fala. Considerando a percepção da fala como um fenômeno bimodal, a consciência fonoarticulatória toma o gesto articulatório como objeto de análise percebendo que os sons se modificam segundo os lugares em que os articuladores entram em contato. A percepção desse processo contribui para que o falante reflita sobre os sons. Por isso é interpretada sendo uma das etapas da consciência fonológica (Santos, Gonçalves \& Vieira, 2017).

A consciência fonoarticulatória (CFA) capacita a criança a pensar sobre os sons permitindo-a relacioná-los aos movimentos que os órgãos fonoarticuladores produzem para criar o som. Estes são partes do corpo humano pertencentes aos sistemas: respiratório e estomatognático. A CFA tanto auxilia na percepção e produção da fala, quanto possibilita a aprendizagem do sistema de escrita alfabético de forma mais simplificada. Estudos indicam que essa modalidade de consciência contribui de fato, para a aquisição e desenvolvimento dos sons da fala (Souza; Mota \& Santos, 2013).

\subsection{Modelos e Métodos de Intervenção Para Desvios Fonológicos ou Aguçamento das Habilidades Fonoarticulatórias}

Observações clínicas têm demonstrado que crianças com desvio fonológico em geral conseguem avanços com terapias fonológicas. Cabe destacar, que existem diversos modelos de terapias fonológicas, como, por exemplo, Modelo de Ciclos, Modelo de Ciclos Modificado, Modelo de Pares Mínimos, Modelos de Oposições Máximas, Modelos Baseados na Hierarquia Implicacional de Traços, Modelo ABAB-Retirada; Terapia Fonológica Baseada no Modelo Implicacional de Complexidade de Traços (Giacchini, 2009).

Sem intenção de exaurir a demonstração de modelos e métodos de intervenção para desvios fonológicos ou aguçamento das habilidades fonoarticulatórias enfoca-se o Sistema de Estimulação NeuroAditiva (SENA@), que é realizado por meio de um software ajustado por um profissional de fonoaudiologia, não é invasivo e traz como benefícios o aprimoramento da capacidade auditiva para receber, perceber e processar informações, capacitando a criança ou adulto submetida a terapia a compreender melhor os sons da fala (Giacchini, Mota \& Mezzomo, 2011).

Menciona-se o Software Auxiliar na Reabilitação de Distúrbios Auditivos (SARDA), desenvolvido em 2008 por um grupo de pesquisadores da UNIVALI baseado no FastForwordLanguage (FFWL), e o próprio treinamento auditivo com o softwareFastForwordLanguage (FFWL), que empregados em terapias fonológicas em crianças com dislexia têm demonstrado evidências do aumento da ativação cerebral na ressonância magnética, indicando a melhoria em habilidades envolvendo linguagem oral, escrita e de consciência fonológica (Comerlatto-Junior, Silva \& Balen, 2010).

Aponta-se o VoiceOnset Time (VOT), que é um parâmetro básico e fundamental com o objetivo de estabelecer o contraste de sonoridade dos fonemas plosivos em crianças com desvios fonológicos que têm dificuldades de pronunciar tais fonemas (Melo et al., 2012).

Cita-se ainda a Terapia fonético/articulatória (TA), que se refere a exercícios que trabalham a região externa do rosto, e depois a parte interna da boca. Além disso, envolve exercícios para melhorar a adequação do tônus, já que ele é essencial para 
o controle motor durante a articulação realizada na fala. O treino motor visa fazer com que a criança com desvios fonológicos tome consciência de que deve ter domínio de se órgãos fonoarticulatórios (Giacchini, 2009).

Esses modelos e métodos são importantes potencializadores do processo de percepção auditiva uma vez que contribuem para saber se a criança com DF consegue perceber os sons da fala (Voiceonset Time),

\subsection{Integração da Percepção Auditiva com a Consciência Fonoarticulatória de Criança com Desvio Fonológico}

A percepção auditiva tem por responsabilidade receber e interpretar os sons ou palavras recebidas, e está diretamente ligada ao processo auditivo, o qual depende da integridade do sistema auditivo, que é pré-requisito essencial para que a criança desenvolva a capacidade de prestar atenção, detectar, discriminar e localizar sons, bem como memorizar e integrar experiências auditivas a fim atingir o reconhecimento e compreensão da fala e sua sonoridade (BrancalionI et al., 2012).

O desenvolvimento das habilidades de linguagem e fala está associado à integridade tanto da maturação neuromuscular quando do sistema sensorial. A criança ao prender um padrão articulatório de uma língua se utiliza de aspectos sensoriais e motores, onde as habilidades auditivas relacionadas à percepção da fala constituem um desses aspectos sensoriais (Caumo \& Ferreira, 2009).

Tanto as privações sensoriais provocadas por ambientes privados ou perdas auditivas provocadas por otite, por exemplo, podem influenciar de modo negativo na aquisição e desenvolvimento da produção da fala e da linguagem de uma criança. Apesar da etiologia do desvio fonológico (DF) ser desconhecida, estudos realizados por Boets et al. (2008) e Santos et al. (2010), indicam que a incapacidade de discriminar auditivamente os sons pode ser um fator da causa ou de agravo do DF (Brancalioni et al., 2012).

Crianças que não apresentam alterações de processamento auditivo central são capazes de detectar mais facilmente os padrões da fala, em relação aos que apresentam. Esse fato lhes possibilita dirigir-se com mais eficiência em direção a estruturas complexas da linguagem. Por outro lado, quando possuem falhas no processamento auditivo podem apresentar dificuldades no processo da linguagem, aprendizagem e comunicação, dificultado o desenvolvimento das habilidades fonológicas essenciais para mapear fonemas e decodificar palavras e frases de modo efetivo e automático (Oliveira, Santos \& Barroso, 2015).

Para que a consciência fonológica se desenvolva de modo efetivo se faz necessário que a criança possua percepção auditiva sem falhas, isto é, tenha integridade auditiva. Como se sabe a consciência fonológica é uma habilidade do ser humano. Através dela habilidade torna-se possível a criança reconhecer que a cadeia sonora da fala encontra-se formada por diferentes sons, o que a leva a compreender que na fala há inúmeras possibilidades de segmentação da sonoridade. Traduzida como um importante auxiliar na produção da fala, a consciência fonológica também facilita o processo de aprendizagem do sistema de escrita do alfabeto (Souza, Mota \& Santos, 2011).

Crianças com desvio fonológico, isto é, dificuldades da linguagem afetadas pela produção da fala, podem ter problemas relacionados a consciência fonológica, é o que demonstrou um estudo objetivando avaliar a relação entre desvios fonológicos e o desenvolvimento das habilidades em consciência fonológica entre dois grupos de crianças: um com desvio fonológico e outro com desenvolvimento fonológico normal (Souza, Mota \& Santos, 2011).

Estudos realizados por Capellini (2012), Silva e Pereira (2013) apontam que desvios fonológicos podem estar associados a falhas na percepção auditiva que, por sua, vez influencia negativamente no desenvolvimento da consciência fonológica. Os pesquisadores sugerem que essas atividades estão interligadas na definição de tarefas importantes, como a representação fonológica estável e assim, o processo de aprendizagem da linguagem e da percepção da segmentação da fala, contribuindo no aprendizado da leitura pela criança em idade escolar (Sordi, 2017). 


\section{Metodologia}

A pesquisa trata-se de uma revisão integrativa com abordagem de natureza qualitativa. A revisão integrativa, segundo Severino (2012) é um método de pesquisa que tem como finalidade sintetizar as pesquisas publicadas, para obter novas conclusões a partir de um tema de interesse. Por sua vez, a abordagem qualitativa permite atribuir sentidos àquilo que é pesquisado, pois busca a compreensão de um determinado fenômeno centrando-se na objetividade (Pereira et al., 2018).

A busca ocorreu no mês de setembro de 2020 na biblioteca eletrônica ScientificElectronic Library Online (SciELO) e na base de dados do Centro Latino- Americano e do Caribe em Ciências da Saúde, mais conhecido como, BIREME, no Índice da Literatura Científica e Técnica da América Latina e Caribe (LILACS), no Banco Virtual de Saúde (BVS).

Como critério de inclusão convencionou-se que seriam artigos científicos publicados no período de 2011 a 2020 com resumos e textos completos disponíveis no idioma português publicados no Brasil, contendo como descritores as palavrasexpressões: percepção auditiva, consciência fonoarticulatória, desvio fonológico em crianças. Foram excluídas todas as publicações que não atingiram os critérios de inclusão.

Foram cumpridas as seguintes etapas: identificação do tema; formulação de uma questão norteadora; busca e seleção da literatura; categorização e avaliação dos estudos; e apresentação da revisão. Para análise das informações, os artigos incluídos foram lidos exaustivamente, além de se realizar uma padronização do conteúdo encontrado de acordo com os objetivos propostos.

A busca inicial das publicações científicas ocorreu por meio do cruzamento dos descritores escolhidos permitindo obter um total de 131 artigos científicos para análise. Em seguida se aplicou os critérios de inclusão da pesquisa e foram excluídas 78 publicações sem relevância para o estudo.

Desse modo, obteve-se 53 artigos publicados no idioma português, disponíveis em textos completos, onde 44 foram excluídos por não atenderem a proposta do estudo, restando 09 artigos para análise e discussão.

Com vistas a ilustrar melhor como se deu a busca na base de dados foi sintetizado no Fluxograma 1. 
Fluxograma 1. Estratégias de busca dos artigos da pesquisa.

\section{ESTRATÉGIA DE BUSCA: SCIELO, BIREME,}

LILACS, BVS.
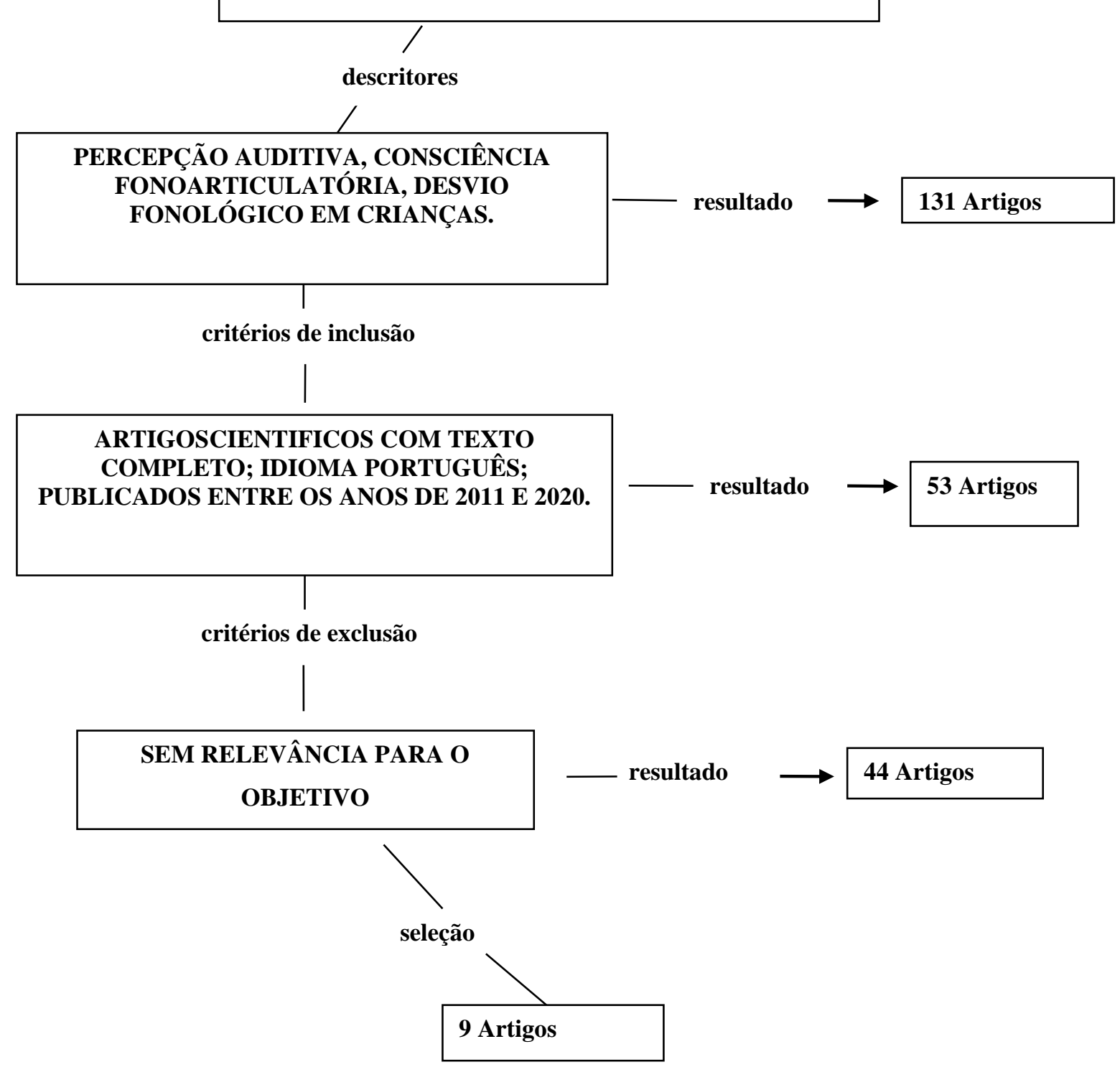

Fonte: Direta (2020).

Dessa maneira, observando o fluxograma é possível perceber que os descritores obtiveram resultados precisos nas bases de dados, isso se dá devido a amplitude dos temas que os descritores abrangem, o que facilita a busca. A percepção auditiva juntamente com a consciência fonoarticulatória e o desvio fonológico são temáticas amplamente discutidas no meio científico, dado a relevância, o que acarreta, ao que se pôde perceber, em resultados mais frequentes nas buscas nas principais bases de dados. No entanto após a aplicação dos critérios de inclusão e exclusão os resultados foram sintetizados, a fim de atender com precisão a temática proposta e o objetivo do estudo. 


\section{Resultados}

A amostra dos estudos encontra-se constituída de 9 artigos indexados nos bancos de dados das fontes citadas. Essas publicações foram analisadas conforme os critérios de inclusão convencionados e os filtros aplicados.

No Gráfico 1 encontra-se a distribuição dos artigos selecionados conforme os periódicos.

Gráfico 1. Distribuição das publicações de acordo com o periódico.

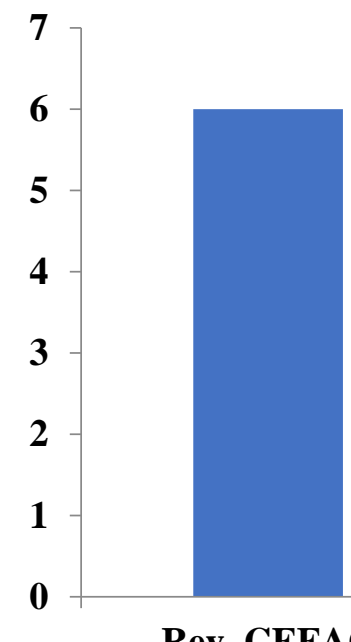

Rev. CEFAC

\section{CoDAS}

Sisturb. Com

\section{J. Soc Bras \\ Fonoaudiol}

Fonte: Direta (2020)

Verificou-se no Gráfico 1 que, a Rev. CEFAC foi o periódico com maior número de publicações (6); seguido das revistas CoDas, Distúrb. Com, J. Soc Bras Fonoaudiol, cada uma com apenas 1 publicação cada.

Também foram analisados os artigos selecionados segundo o ano de publicação, como segue no Gráfico 2.

Gráfico 2. Análise dos artigos selecionados segundo o ano de publicação.

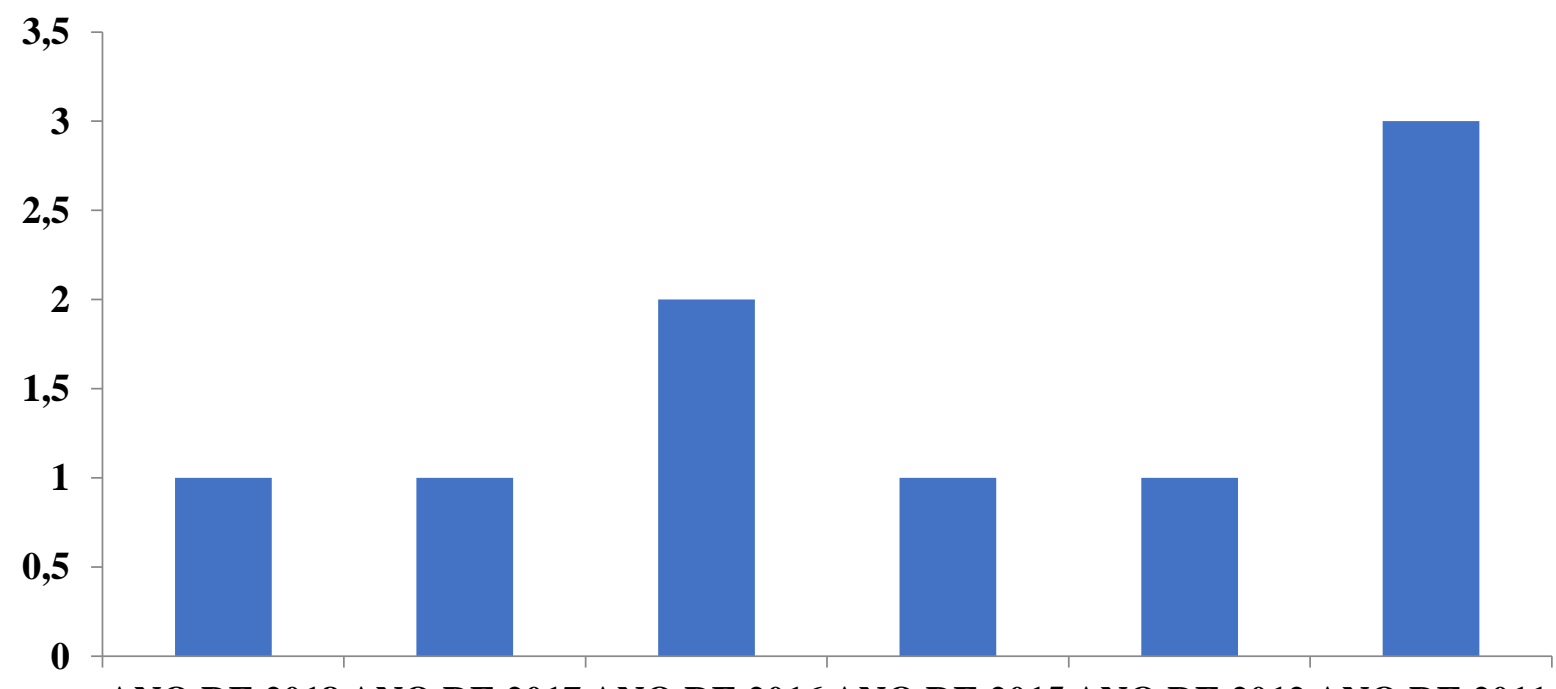

ANO DE 2018 ANO DE 2017 ANO DE 2016 ANO DE 2015 ANO DE 2012 ANO DE 2011

Fonte: Direta (2020) 
Constatou-se no Gráfico 2 que o ano de 2011 foi aquele com maior número de publicações (3); seguido dos anos de 2016 com 2 publicações e dos anos de 2018, 2017, 2015 e 2012, cada um com apenas 1 publicação. Os dados evidenciam que nos anos de 2020, 2019, 2014, 2013, não foi publicado nenhum artigo sobre a temática de estudo.

Os 9 (nove) artigos selecionados estão apresentados no Quadro 1 a seguir, de acordo com autor, ano de publicação, título, objetivo e conclusão.

Quadro 1. Distribuição das publicações seguindo os descritores estabelecidos e filtros aplicados.

\begin{tabular}{|c|c|c|c|c|}
\hline Autor/ano & Título & Objetivo & Metodologia & Resultado ou Conclusão \\
\hline $\begin{array}{l}\text { Donicht, } \\
\text { Ceron \& } \\
\text { Soares } \\
(2018)\end{array}$ & $\begin{array}{l}\text { Ocorrência do desvio } \\
\text { fonológico } \mathrm{e}^{\mathrm{de}} \\
\text { processos fonológicos } \\
\text { em } \\
\text { fonológica } \\
\text { atípica. }\end{array}$ & $\begin{array}{l}\text { Verificar e correlacionar os } \\
\text { erros ortográficos presentes } \\
\text { nas produções escritas ao } \\
\text { desempenho em habilidades } \\
\text { de consciência fonológica de } \\
\text { crianças em diferentes anos } \\
\text { escolares, com } \\
\text { desenvolvimento fonológico } \\
\text { típico e atípico. }\end{array}$ & $\begin{array}{l}\text { Estudo de } \\
\text { caso. }\end{array}$ & $\begin{array}{l}\text { A correlação foi inversamente } \\
\text { proporcional entre o desempenho } \\
\text { em consciência fonológica e o } \\
\text { número de erros ortográficos } \\
\text { (aqueles que alteram a estrutura } \\
\text { silábica) para ambos os grupos, } \\
\text { demonstrando que quanto mais } \\
\text { erros deste tipo, menor o } \\
\text { desempenho em consciência } \\
\text { fonológica silábica, fonêmica e } \\
\text { total. }\end{array}$ \\
\hline $\begin{array}{l}\text { Barrozo } \\
\text { et al., } \\
(2017)\end{array}$ & $\begin{array}{lr}\text { Sensibilidade } & \text { e } \\
\text { especificidade } & \text { da } \\
\text { porcentagem } & \text { de } \\
\text { consoantes } & \text { corretas } \\
\text { revisada } & \text { na } \\
\text { identificação } & \text { do } \\
\text { transtorno fonológico. }\end{array}$ & $\begin{array}{l}\text { Verificar a sensibilidade, } \\
\text { especificidade e estabelecer } \\
\text { pontos de corte para o índice } \\
\text { Porcentagem de Consoantes } \\
\text { Corretas Revisado (PCC-R) } \\
\text { em crianças com e sem } \\
\text { transtorno fonológico } \\
\text { falantes do Português } \\
\text { Brasileiro. }\end{array}$ & $\begin{array}{l}\text { Estudo de } \\
\text { caso. }\end{array}$ & $\begin{array}{l}\text { Dada a alta sensibilidade e } \\
\text { especificidade do PCC-R, o índice } \\
\text { foi efetivo na discriminação e } \\
\text { identificação de crianças com e } \\
\text { sem transtorno fonológico. }\end{array}$ \\
\hline $\begin{array}{l}\text { Brancalion } \\
\text { \& Soares } \\
(2016)\end{array}$ & $\begin{array}{l}\text { Palavras-estímulo } \\
\text { favorecedoras para o } \\
\text { tratamento do desvio } \\
\text { fonológico em onset } \\
\text { simples. }\end{array}$ & \begin{tabular}{lr}
\multicolumn{2}{l}{ Propor e analisar listas com } \\
palavras-estímulo & em \\
contextos & linguísticos \\
favorecedores & para \\
segmentos-alvo na posição \\
de onset simples, utilizando \\
um padrão de programação \\
para pontuar o nível de \\
favorecimento & dessas \\
palavras. &
\end{tabular} & $\begin{array}{c}\text { Padrão de } \\
\text { programação. }\end{array}$ & $\begin{array}{l}\text { O padrão de programação } \\
\text { desenvolvido foi eficiente para } \\
\text { pontuar o nível de favorecimento } \\
\text { das palavras-estímulo. Além } \\
\text { disso, deve haver uma preferência } \\
\text { por palavras-estímulo } \\
\text { favorecedoras, ou que alcançam } \\
\text { maior pontuação, porém nem } \\
\text { sempre essas palavras são as mais } \\
\text { adequadas para o tratamento de } \\
\text { qualquer sistema fonológico } \\
\text { desviante. }\end{array}$ \\
\hline $\begin{array}{l}\text { Dias \& } \\
\text { Mezzomo } \\
(2016)\end{array}$ & $\begin{array}{l}\text { Terapia } \\
\text { fonoaudiológica para os } \\
\text { desvios fonológicos } \\
\text { com base na } \\
\text { estimulação } \quad \text { de } \\
\text { habilidades } \\
\text { consciência fonológica. }\end{array}$ & $\begin{array}{l}\text { Propor e aplicar uma } \\
\text { abordagem terapêutica para } \\
\text { os desvios fonológicos com } \\
\text { base na estimulação de } \\
\text { habilidades em consciência } \\
\text { fonológica e palavras com } \\
\text { estrutura } \\
\text { controlada. fonológica }\end{array}$ & $\begin{array}{l}\text { Estudo de } \\
\text { caso. }\end{array}$ & $\begin{array}{l}\text { A abordagem terapêutica aplicada } \\
\text { promoveu a reorganização do } \\
\text { sistema fonológico nos três casos } \\
\text { estudados. A estrutura fonológica } \\
\text { das palavras que compõem tarefas } \\
\text { de consciência fonológica parece } \\
\text { ter impacto no desempenho das } \\
\text { crianças observadas, face às tarefas } \\
\text { de consciência fonológicas } \\
\text { propostas. }\end{array}$ \\
\hline $\begin{array}{l}\text { Vargas, } \\
\text { Mezomo \& } \\
\text { Freitas } \\
(2015) .\end{array}$ & $\begin{array}{l}\text { Atraso de linguagem e } \\
\text { desvio fonológico: um } \\
\text { continuum ou duas } \\
\text { patologia distintas? }\end{array}$ & $\begin{array}{l}\text { Estudar e verificar se o } \\
\text { desvio fonológico é um } \\
\text { continuum do atraso de } \\
\text { linguagem, ou seja, se } \\
\text { crianças com } \\
\text { desenvolvimento fonológico }\end{array}$ & $\begin{array}{l}\text { Estudo de } \\
\text { caso. }\end{array}$ & $\begin{array}{l}\text { Os achados deste trabalho } \\
\text { corroboram a literatura, no sentido } \\
\text { de que o desvio fonológico se } \\
\text { refere a uma alteração no nível } \\
\text { fonológico apenas, não sendo }\end{array}$ \\
\hline
\end{tabular}




\begin{tabular}{|c|c|c|c|c|}
\hline & & $\begin{array}{l}\text { atípico possuíam } \\
\text { anteriormente algum atraso } \\
\text { no desenvolvimento de } \\
\text { linguagem. }\end{array}$ & & $\begin{array}{l}\text { considerado como um continuum } \\
\text { do atraso de linguagem. }\end{array}$ \\
\hline $\begin{array}{l}\text { Melo et al., } \\
\text { (2012). }\end{array}$ & $\begin{array}{l}\text { Desvio fonológico e a } \\
\text { dificuldade com a } \\
\text { distinção do traço [voz] } \\
\text { dos fonemas plosivos - } \\
\text { dados de produção e } \\
\text { percepção do contraste } \\
\text { de sonoridade. }\end{array}$ & $\begin{array}{l}\text { Comparar os valores de } \\
\text { voiceonset time (VOT) de } \\
\text { fonemas plosivos, } \\
\text { produzidos por criançascom } \\
\text { desvio fonológico e } \\
\text { dificuldade na produção do } \\
\text { contraste de sonoridade, } \\
\text { classificados comosurdos e } \\
\text { sonoros a partir de uma } \\
\text { análise perceptiva auditiva. }\end{array}$ & $\begin{array}{l}\text { Estudo de } \\
\text { caso. }\end{array}$ & $\begin{array}{l}\text { De maneira geral, constatou-se } \\
\text { que o VOT não é uma pista } \\
\text { determinante para a percepção da } \\
\text { distinção da sonoridade dos casos } \\
\text { desviantes. No entanto, esta pista } \\
\text { mostrou exercer influência na } \\
\text { discriminaçãodos fonemas de } \\
\text { acordo com o ponto articulatório, } \\
\text { também no desvio fonológico. }\end{array}$ \\
\hline $\begin{array}{l}\text { Giacchini, } \\
\text { Mota \& } \\
\text { Mezzomo } \\
(2011)\end{array}$ & $\begin{array}{l}\text { Diferentes modelos de } \\
\text { terapia fonoaudiológica } \\
\text { nos casos de } \\
\text { simplificação do } \\
\text { compet } \\
\text { lomplexor com } \\
\text { compensatório. }\end{array}$ & $\begin{array}{llr}\text { Verificar } & \text { a abordagem } \\
\text { terapêutica } & \text { mais eficaz às } \\
\text { crianças com desvio } \\
\text { fonológico que realizam a } \\
\text { estratégia de alongamento } \\
\text { compensatório (EAC) nos } \\
\text { casos de } \mathrm{C} 1 \mathrm{C} 2 \mathrm{~V} \rightarrow \mathrm{C} 1 \mathrm{~V} \text {. }\end{array}$ & $\begin{array}{l}\text { Estudo de } \\
\text { caso. }\end{array}$ & $\begin{array}{l}\text { As crianças que empregam a EAC } \\
\text { apresentaram melhores resultados } \\
\text { quando submetidas à terapia que } \\
\text { promoveu implementação fonética } \\
\text { e não a organização fonológica, } \\
\text { visto que os pacientes expostos à } \\
\text { TA obtiveram progressos mais } \\
\text { rápidos quando comparados ao } \\
\text { modelo fonológico }\end{array}$ \\
\hline $\begin{array}{l}\text { Souza; } \\
\text { Mota; } \\
\text { Santos } \\
\text { (2011). }\end{array}$ & $\begin{array}{l}\text { A consciência } \\
\text { fonoarticulatória em } \\
\text { crianças com desvio } \\
\text { fonológico. }\end{array}$ & $\begin{array}{l}\text { Investigar a consciência } \\
\text { fonoarticulatória de crianças } \\
\text { com desenvolvimento } \\
\text { fonológico normal de acordo } \\
\text { com gênero, idade e } \\
\text { escolaridade e analisar os } \\
\text { desempenhos em tarefas de } \\
\text { percepção e produção da } \\
\text { fala. }\end{array}$ & $\begin{array}{l}\text { Estudo de } \\
\text { caso. }\end{array}$ & $\begin{array}{l}\text { A consciência fonoarticulatória } \\
\text { aprimora-se de acordo com idade e } \\
\text { escolaridade. Crianças do gênero } \\
\text { feminino apresentam melhor } \\
\text { desempenho do que as do gênero } \\
\text { masculino. Quanto melhor o } \\
\text { desempenho nas tarefas de } \\
\text { percepção, melhor o desempenho } \\
\text { nas tarefas de produção da } \\
\text { consciência fonoarticulatória. }\end{array}$ \\
\hline $\begin{array}{l}\text { Souza; } \\
\text { Mota; } \\
\text { Santos } \\
(2011)\end{array}$ & $\begin{array}{l}\text { O desenvolvimento da } \\
\text { consciência } \\
\text { fonoarticulatória e a } \\
\text { relação entre a } \\
\text { percepção e a produção } \\
\text { do gesto } \\
\text { fonoarticulatório }\end{array}$ & $\begin{array}{l}\text { Verificar as habilidades em } \\
\text { consciência fonoarticulatória } \\
\text { de crianças com desvio } \\
\text { fonológico, comparando-as } \\
\text { com as habilidades em } \\
\text { consciência fonoarticulatória } \\
\text { de crianças com } \\
\text { desenvolvimento fonológico } \\
\text { normal. }\end{array}$ & $\begin{array}{l}\text { Estudo de } \\
\text { caso. }\end{array}$ & $\begin{array}{l}\text { Crianças com desvio fonológico } \\
\text { apresentam maior dificuldade em } \\
\text { habilidades de consciência } \\
\text { fonoarticulatória se comparadas a } \\
\text { crianças com desenvolvimento } \\
\text { fonológico normal. }\end{array}$ \\
\hline
\end{tabular}

Fonte: Direta (2020).

O Quadro 1 permite observar que o tema central abordado pelos autores corresponde aos critérios de inclusão que tem a seguinte combinação de descritores: percepção auditiva, consciência fonoarticulatória, desvio fonológico em crianças.

Pode-se observar que a maioria dos autores enfatizam a questão do desvio fonológico, assim, a maioria dos estudos elegíveis à pesquisa abordam a temática, o que sugere um maior enfoque sobre o determinado tema.

\section{Discussão}

Mediante a revisão integrativa da literatura detalhada dos artigos selecionados, os resultados foram evidenciados demonstrando a relação da percepção auditiva com a consciência fonoarticulatória de criança com desvio fonológico.

Giacchini, Mota e Mezzomo (2011) esclarecem que quando a criança não consegue de forma espontânea adquirir o sistema fonológico na sequência e faixa etária comum, ela possui desvio fonológico, o qual pode caracterizado como omissões, substituições ou distorções dos sons da fala. 
Reforçando essa concepção, Brancalioni e Soares (2016) por meio de padrão de programação, em linguagem Java, para identificar a pontuação das palavras-estímulo observaram que o desvio fonológico (DF) possui características tais como substituição, apagamento ou transposição dos sons da fala, mesmo em crianças que não apresentam alteração orgânica. Além disso, que esse desvio interfere em diferentes graus a capacidade de fala, e se encontra presente com elevada incidência em crianças.

Um estudo de caso realizado pelos pesquisadores Souza, Mota e Santos (2011) demonstrou que crianças com desvio fonológico possuem algumas características que são similares, como faixa etária superior a quatro anos de idade, fala espontânea desviando da pronúncia adulta alvo, e boa audição para a fala. E que crianças com anormalidade fisiológica ou anatômica apresentada nos órgãos de produção da fala, ou ainda disfunção neurológica, não se inserem nas características padrões de desvio fonológico.

Vargas, Mezzomo e Freitas (2015) verificaram em um estudo de caso realizado com um grupo de 10 crianças com atraso de linguagem que o desvio fonológico diz respeito a uma alteração situada somente no nível da fonologia e só dela. O estudo evidenciou que esse tipo de desvio se dá porque existe uma desorganização no mecanismo dos sons da língua, já que não foram detectadas alterações orgânicas, que provocassem o DF.

Donicht, Ceron e Soares (2019) em uma pesquisa envolvendo com crianças com desenvolvimento fonológico típico (GDFT) e com desenvolvimento fonológico atípico constataram a existência da consciência fonológica e que ela de fato é a responsável pela capacidade de pensar, refletir e manipular conscientemente os sons da fala. Além disso, constataram a interrelação existente entre as habilidades da consciência fonológica e as habilidades da linguagem oral, e perceberam que alterações em uma dessas duas dimensões podem provocar desvios fonológicos, e dificuldades em aprender o código escrito.

Dias e Mezzomo (2016) constataram que crianças com desvio fonológico e poucas habilidades em consciência fonológica apresentam dificuldades no processo de alfabetização. Dessa forma, perceberam a necessidade da estimulação dessas habilidades em terapias com crianças com esse tipo de desvio, uma vez que essa estimulação pode proporcionar a restruturação do sistema fonológico, melhorando sua capacidade de pensar sobre os sons da fala. Com fundamento na pesquisa desses autores entendeu-se que estudos da consciência fonológica não devem ser realizados como se ela fosse independente, mas considerandoa como integrante da articulação e intervenção fonológica.

Melo et al. (2012) em estudos relacionado aos valores de voice onset time (VOT) de fonemas plosivos, produzidos por crianças com desvio fonológico, sugerem que crianças com esse tipo de desvio apresentam em alguns casos determinadas dificuldades em operar todos os parâmetros acústicos que promovem a produção dos fonemas. Um dessas dificuldades é imaturidade fisiológica da criança.

Ao realizarem uma pesquisa envolvendo crianças da Educação Infantil e do Ensino Fundamental, Souza, Mota e Santos (2011) observaram que quando uma criança submetida a tarefa de percepção auditiva atinge um bom desempenho, ela também tem o mesmo desempenho em tarefa de produção. Esse resultado sugere que quando determinadas áreas do cérebro da criança são ativadas durante a produção da fala, também é ativada a percepção auditiva.

Estudo sistemático realizado por Carvalho, Novelli e Santos (2015) identificaram que existe relação entre desvio fonológico e habilidades do processamento auditivo, já que constataram em sua investigação que crianças com fala desviante apresentam desempenhos inferiores em comparação às crianças sem desvios fonológicos, o que denota importância da percepção auditiva da criança para seu desenvolvimento da fala e da linguagem, tanto oral quanto escrita. 


\section{Conclusão}

De acordo com os resultados apresentados nesse estudo, foi possível constatar que desvios fonológicos em crianças podem estar relacionados a falhas na percepção auditiva que, por sua, vez, influência de modo negativo no desenvolvimento da consciência fonológica.

Em relação aos recursos fonoterápicos que podem ajudar na percepção auditiva da fala de crianças com desvio fonológico os resultados obtidos apontaram que existem diversos deles, como o Sistema de Estimulação NeuroAditiva (SENA@), o Software Auxiliar na Reabilitação de Distúrbios Auditivos (SARDA, o VoiceOnset Time (VOT), sendo todos eles importantes potencializadores do processo de percepção auditiva uma vez que contribuem para saber se a criança com DF consegue perceber os sons da fala (Voiceonset Time).

Desse modo, tendo em vista a relevância de se compreender a relação da percepção auditiva com a consciência fonoarticulatória de criança com desvio fonológico, faz-se necessário o desenvolvimento de mais estudos científicos que abordem a temática. Sabendo que a percepção auditiva é uma condição inerente ao ser humano, o conhecimento total acerca dos fatores relacionados com o mesmo que podem influenciar positiva ou negativamente na consciência fonoarticulatória do indivíduo é de irrefutável relevância. Portanto, a abordagem faz-se válida e pertinente à necessidade científica de conhecer e se aprofundar na temática proposta.

\section{Referências}

Afonso, L. (2015). O surgimento da capacidade da fala. https://showcommerce-files.net.br/arquivos/1533503227o-surgimento-da-capacidade-da-fala.pdf.

Bardin, L. (2008). Método dialético em metodologia científica. (53a ed.), Edições.

Barrozo, T. F., et al. (2017). Sensibilidade e especificidade da porcentagem de consoantes corretas revisada na identificação do transtorno fonológico. CoDAS, 29 (3). https://www.scielo.br/scielo.php?pid=S2317-17822017000300500\&script=sci_abstract\&tlng=pt.

Brancalioni, A. R et al. (2012). A relação entre a discriminação auditiva e o desvio fonológico. J Soc Bras Fonoaudiol. 24 (2). https://www.scielo.br/pdf/jsbf/v24n2/pt_12.pdf.

Buriti, A. K. L \& Rosa, M. R. D. (2014) Percepção auditiva em escolares com dislexia: uma revisão sistemática. Rev. psicop., São Paulo, 31 (94), 82-8. http://pepsic.bvsalud.org/scielo.php?script=sci_arttext\&pid=S0103-84862014000100010.

Carvalho, N. G., Novelli, C. V. L \& Santos, M. F. C. (2015). Fatores na infância e adolescência que podem influenciar o processamento auditivo: revisão sistemática. Rev. CEFAC, 17 (5), 1590-1603. https://www.scielo.br/pdf/rcefac/v17n5/1982-0216-rcefac-17-05-01590.pdf.

Caumo, D. T. M., \& Ferreira, M. I. D. C. (2009). Relação entre desvios fonológicos e processamento auditivo. Rev soc. bras. fonoaudiol., São Paulo, 14 (2), 234-40. https://www.scielo.br/pdf/rsbf/v14n2/15.pdf.

Comerlatto Junior, A. A., Silva, M. P., \& Balen, S. A. (2010). Software para reabilitação auditiva de crianças com distúrbios no processamento auditivo central. Rev Neurocienc, 18 (4), 454-462. http://www.revistaneurociencias.com.br/edicoes/2010/RN1804/509\%20original.pdf.

Cysneiros, H. R. S et al. (2016) Relação entre percepção auditiva e produção vocal em implantados cocleares: uma revisão sistemática. CoDAS, [on line] 28 (5) 634-639. https://www.scielo.br/pdf/codas/v28n5/2317-1782-codas-2317-178220162015165.pdf.

Errobidart, H. A., et al. (2014). Ouvido mecânico: um dispositivo experimental para o estudo da propagacão e transmissão de uma onda sonora. Rev. Bras. de Ens. de Fis. 36 (1). https://www.scielo.br/pdf/rbef/v36n1/25.pdf.

Gianchinni, V. (2009). Aplicação de modelos terapêuticos de base fonética e fonológica utilizados para a superação das alterações da fala. 2009. 110f. Dissertação, Mestrado em Disturbios da Comunicação Humana - Rio Grande do Sul, UFSM, https://repositorio.ufsm.br/bitstream/handle/1/645 4/GIACCHINI\%2c\%20VANESSA.pdf?sequence=1\&isAllowed=y.

Giacchini, V., Mota, H. B \& Mezzomo, C. L. (2011). Diferentes modelos de terapia fonoaudiológica nos casos de simplificação do onset complexo com alongamento compensatório. Rev. CEFAC, 13 (1) 57-64. https://www.scielo.br/pdf/rcefac/v13n1/a07v13n1..

Goméz, A. M. S., \& Terán, N. E. (2015). Dificuldades de aprendizagem: detecção e estratégias de ajuda. (4a ed.), Cultural SA.

Melo, R. M et al. (2012). Desvio fonológico e a dificuldade com a distinção do traço [voz] dos fonemas plosivos - dados de produção e percepção do contraste de sonoridade. Rev. CEFAC, 14 (1), 18-29. https://www.redalyc.org/pdf/1693/169321453013.pdf.

Mezzomo, C. L., Mota, H. B \& Dias, R. F. (2010) Desvio fonológico: aspecto sobre a produção, percepção e escrita. Rev. soc. bras. fonoaudiol. 15 (4) https://www.scielo.br/scielo.php?pid=S1516-80342010000400013\&script=sci_arttext. 
Research, Society and Development, v. 10, n. 1, e51012020, 2021

(CC BY 4.0) | ISSN 2525-3409 | DOI: http://dx.doi.org/10.33448/rsd-v10i1.12020

Moreira, A. I. A. (2013). Níveis de consciência fonológica. 2013.134f. Dissertação [Mestrado em Níveis de Consciência Fonológica] - Portuhal, Universidade Portucalense. http://repositorio.uportu.pt/xmlui/bitstream/handle/11328/675/TMOE\%205.pdf?sequence=1.

Oliveira, H. B. (2013). Potenciais evocados auditivos em indivíduos com hipotireoidismo congênito: uma revisão sistemática da literatura científica. Rev. Ciênc. Méd. Biol., Salvador, 12, 486-491. https://portalseer.ufba.br/index.php/cmbio/article/view/9198/6761.

Oliveira, A. P., Santos, T. M. M \& Barreiro, F. C. A. B. (2015). Associação entre desvio fonológico e distúrbio do processamento auditivo central: revisão da literatura. Rev. Equil.Corp. Saú, 7 (1), 21-4. revista.pgsskroton.com/index.php/reces/article/view/3145/2897.

Pagliarin, K. C et al. (2011). Relação entre gravidade do desvio fonológico e fatores familiares. Rev. CEFAC, 13 (3), 414-427. https://www.scielo.br/pdf/rcefac/v13n3/89-09.pdf.

Pereira, A.S. et al. (2018). Metodologia da pesquisa científica. Ed. UAB/NTE/UFSM.

Rabelo, A. T. V et al. (2015). Alteracões fonoaudiológicas em crianças de escolas públicas em Belo Horizonte. Rev. Paul Pediatri, 33 (4), 453-459. https://www.scielo.br/pdf/rpp/v33n4/pt_0103-0582-rpp-33-04-0453.pdf.

Santos, P. O., Gonçalves, G. F \& Vieira, M. J. B. (2017). Habilidades em consciência fonoarticulatória de crianças monolíngues e bilíngues (pomerano/português): dados de arroio do padre/rs. Rev.Eletr. do Netlli, 3 (6). http://periodicos.urca.br/ojs/index.php/MigREN/article/view/1390/1188.

Severino, A. J. (2012) Metodologia do trabalho científico. (14a ed.), Cortez.

Sordi, C. (2017). Alfabetização e consciência fonológica: considerações teóricas sobre sua relação com o sistema alfabético. Ens. Tecnol. R., Londrina, 1 (1), 33-45. https://.periodicos.utfpr.edu.br/etr//article/download/5944/4413.

Souza, D. V., Mota, H. B \& Santos, R. M. A. (2011). consciência fonoarticulatória em crianças com desvio fonológico. Rev. CEFAC, 13 (2), 196-204. https://www.scielo.br/pdf/rcefac/v13n2/02-10.pdf.

Souza, D. V. A. (2009). consciência fonoarticulatória em crianças com desenvolvimento fonológico normal e desviante. 2009. 99f. Dissertação [Mestrado em Distúrbios da Comunicação Humana] - Rio Grande do Sul, UFSM-RS.

Terto, S. S. M \& Lemos, S. M. A. (2011). Aspectos temporais auditivos: produção de conhecimento em quatro periódicos nacionais. Rev. CEFAC, 13 (5), 926936. https://www.scielo.br/scielo.php?script=sci_abstract\&pid=S151618462011000500018\&lng=pt\&nrm=iso. 